\title{
RELIABILITY CONSIDERATIONS OF FLIP CHIP COMPONENTS FOR AUTOMOTIVE ELECTRONIC APPLICATIONS
}

\author{
KEISUKE SUGIYAMA, ISAO BANSAKU, NAOHARU TSUZIMOTO and IWAO TACHIKAWA \\ Sanken Electric Co. Ltd., Microelectronics Division, 677 Onohara Shimoakasaka, Kawagoe, Saitama, \\ Japan.
}

\begin{abstract}
Electronic devices for automotive electronic applications have to be operated under extreme environmental conditions and therefore are required to have higher reliability compared with general electronic equipment. Recently automotive voltage regulators, ignition systems, etc. have been changing from mechanical constructions to electronic ones using thick film technology.

This paper presents results that shows that our flip chip IC technology can satisfy the high reliability requirements of automobile electronics.
\end{abstract}

\section{INTRODUCTION}

Thick film integrated circuits using hybrid circuits are being applied to automotive electronics and the volume of such business is increasing every year. Such a market requires high reliability in the component and in the circuit, particularly from the point of view of maintaining safety. Furthermore the environmental conditions that automobile electronics find themselves in are continually changing, and are often extreme, and it is therefore, necessary to establish methods of operation that take into account the various extreme conditions under which the circuits will operate.

Up to the present time hybrid circuits involving integrated circuits have been applied to many electronic equipments. However, in the case of automotive applications completely different design standards must be introduced for the hybrid integrated circuits. Table I shows a sample of the type of reliability tests and conditions that must be met.

Conditions for temperature, humidity, vibration and surge voltage are very strict as compared with other normal applications. The reliability of hybrid ICs are limited by various factors including; surface passivation technology of the active devices, the bonding technology used, the adhesive strength between substrate and printed thick film, and by other factors. The most important factor is the bonding technology used for the devices in attaching them to the circuit. Most commonly the bonding method used for active devices has been die attachment by eutectic technology or the use of conductive resin. Also the gold or
TABLE I

Environmental test conditions for automotive electronic equipment (1).

\begin{tabular}{ll}
\hline Test & Condition \\
\hline High temperature storage & $\mathrm{Ta}=120^{\circ} \mathrm{C}, 94 \mathrm{hrs}$ \\
Low temperature storage & $\mathrm{Ta}=-40^{\circ} \mathrm{C}, 70 \mathrm{hrs}$ \\
Thermal shock & $120^{\circ} \mathrm{C}-40^{\circ} \mathrm{C}$ \\
& $(1 \mathrm{hr})(1 \mathrm{hr})$ \\
& $100^{\circ} \mathrm{C} \rightleftharpoons$ cycles $)$ \\
Temperature cycling & $(1 \mathrm{hr})(1 \mathrm{hr})(1 \mathrm{hr})$ \\
& $\mathrm{Ta}=100^{\circ} \mathrm{C}, 118 \mathrm{hrs}$ \\
High temperature electrical & \\
endurance & $\mathrm{Ta}=60^{\circ} \mathrm{C}, \mathrm{RH}=95 \%, 94 \mathrm{hrs}$ \\
Humidity (steady state) & $\mathrm{Vp}=300 \mathrm{~V}, \mathrm{~T}=300 \mu \mathrm{sec}$ \\
Surge voltage endurance & $\mathrm{f}=1 / 30,96 \mathrm{hrs}$ \\
\hline
\end{tabular}

aluminium wires used are bonded to gold conductive pads using thermocompression technology or ultrasonic bonding techniques. Bonding strength of wires attached by these latter methods is usually of the order of 10 granis per wire at most, and this level cannot satisfy the vibration and temperature criteria for automotive electronics. However, bonding strengths for the reflow soldering technique can be over 10 times stronger than the wire bonding method and thus solder bonding technology is a most suitable method for attaching ICs and other flip chip devices to automotive electronic circuits.

Furthermore, chip capacitors and other components can also be attached to the substrates by reflow 
soldering technology. This can be done at the same time at which the integrated circuits are attached. The system therefore offers economical advantage which is further improved as the technology needs no precious metals like gold in its realisation.

This paper reports the results of various bonding strength reliability tests and also electrical reliability tests on flip chip attached integrated circuits.

\section{SOLDER BUMP STRUCTURE AND SOLDER REFLOW BONDING}

The required criteria for using flip chip technology are that the components would show:-

1) Stable and reliable electrical characteristics

2) Easy, strong and reliable bondability.

To realise the latter the structure of the solder bumps needs to be complex. Figure 1 shows the type of structure used in our work.

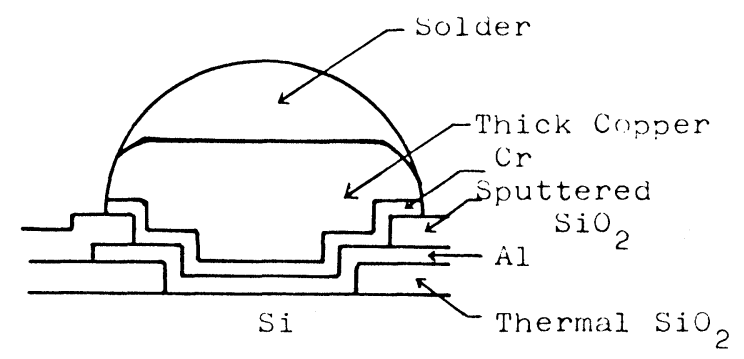

FIGURE 1 Bump structure.

To obtain easy strong and reliable bonding the bump has to be solder covered. A thick copper layer has been used to prevent the chip from touching the solder covered conductor at the time of bonding, in order to improve the reliability of the bonding process.

Chromium is used to obtain good adhesion between the copper and the aluminium or the sputtered silicon dioxide which is often used to protect the integrated circuit chip surface from being scratched after manufacture.

Figure 2 shows diagrammatically the solder reflow bonding method used for attaching flip chip components to the bonding pad conductors of hybrid circuits. The flip chip integrated circuits and other passive components are placed one after another on the surface of the circuit and held in position by the viscosity of the resin flux used. After all the active and passive components have been placed into position on

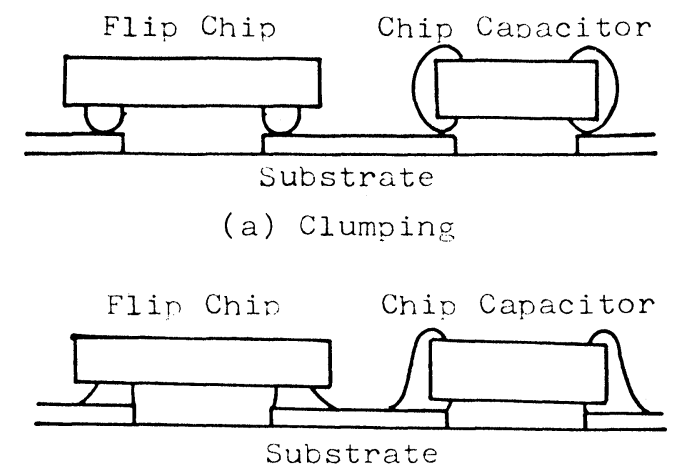

(b) Solder Reflow

FIGURE 2 Bonding process.

the bonding pads of the interconnection circuit they are solder reflowed simultaneously in a solder reflow furnace.

A side view of a component attached by the solder reflow bonding process is shown in Photo 1 . This was obtained using a scanning electron microscope.

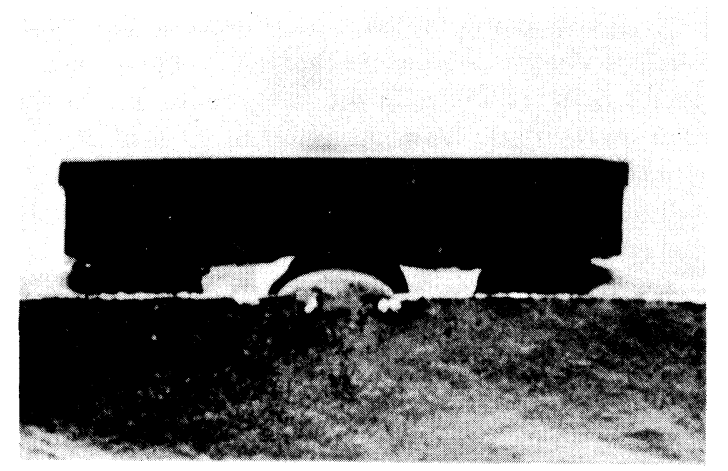

PHOTO 1 Side view of solder reflow bonded component (length of component $0.15 \mathrm{~mm}$ ).

\section{RELIABILITY OF BONDING STRENGTH}

The shear strength per single bump of a flip chip component attached by the technology described above has been measured. Figure 3 gives a histogram showing the distribution of results obtained for one hundred bumps. These bumps were about 220 microns in diameter. Even the minimum value of $150 \mathrm{~g}$ exceeds the strength required for automotive electronic components. When flip chip devices are bonded on to thick film conductors by the solder reflow bonding technology, the distribution of bonding strength per chip is as shown in Figure 4. These tested samples were 


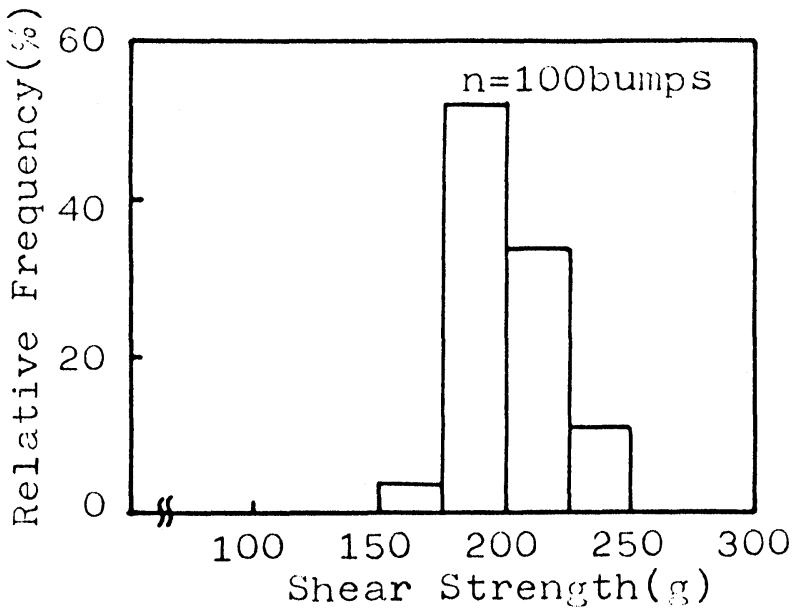

FIGURE 3 Shear strength per one bump.

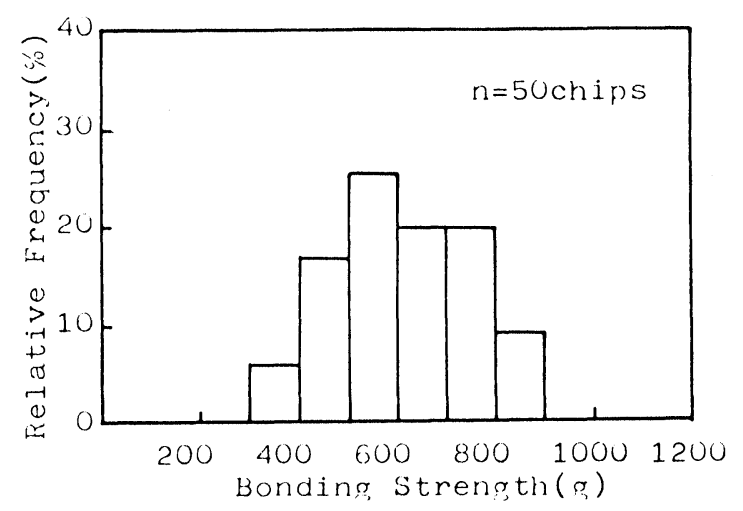

FIGURE 4 Bonding strength per one chip.

standard flip chips with four bumps each and the substrate was a solder dipped printed palladium/silver conductor.

Reliability of bonding strength under various environmental tests has been examined. Environmental temperature conditions for automotive electronics depends on simulating conditions due to the weather and due to heat conduction and radiation from the engine. Of special importance is the maximum temperature experienced by a circuit placed near the distributor or the alternator housing in the engine compartment. Such a circuit can reach temperatures ranging from $90^{\circ} \mathrm{C}$ to $130^{\circ} \mathrm{C}$ as shown in Figure 5. Also the minimum temperatures the circuits will be required to operate under must be considered and starting temperatures as low $-30^{\circ} \mathrm{C}$ to $-40^{\circ} \mathrm{C}$ can be experienced, (see Figure 6) ${ }^{1}$. From these

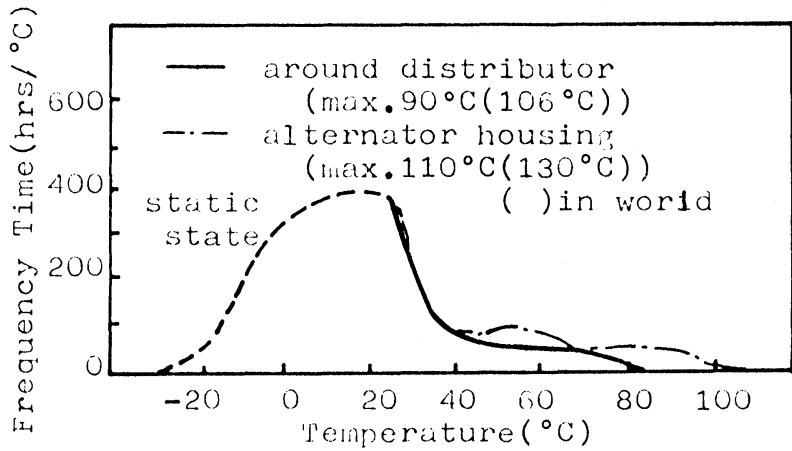

FIGURE 5 Frequency of occurrence of various temperatures at two selected positions in the engine compartment of automobiles both in Japan and averaged over the whole world over a period of one year.

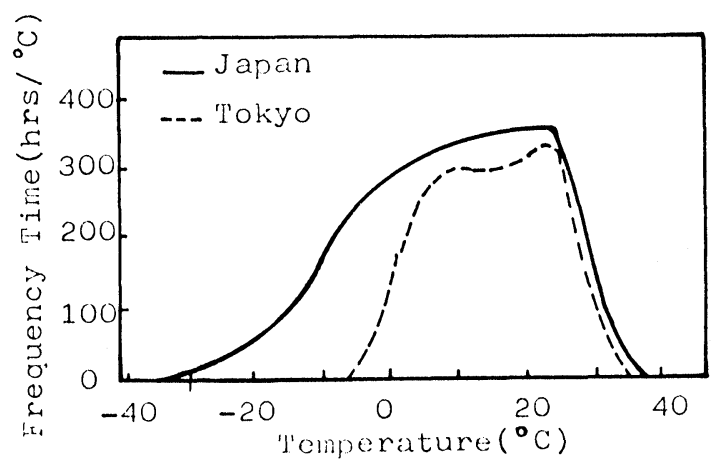

FIGURE 6 Frequency of occurrence of ambient temperatures experienced in Japan over a period of 1 year.

considerations it was decided that the temperature conditions required for storage of the bonded devices should be fixed at $+130^{\circ} \mathrm{C}$ and $-40^{\circ} \mathrm{C}$. Twenty chips were randomly selected for bonding strength measurements after having been stored under these extreme conditions for varying periods of time. The results are shown in Figures 7 and 8. This data shows that the bonding strength was negligibly affected by either the high or low temperature storage test.

The rate of change of temperature inside the engine compartment also needs to be considered. This can change rapidly particularly for a car started in a cold climatic condition as the temperature in the engine compartment can reach $100^{\circ} \mathrm{C}$ in only a few minutes. ${ }^{2}$ To test the effect of such rapid changes in temperature on flip chip bonded integrated circuits, chips attached to substrates were subject to the test conditions shown in Figure 9. 500 Cycles of this temperature variation were performed. 


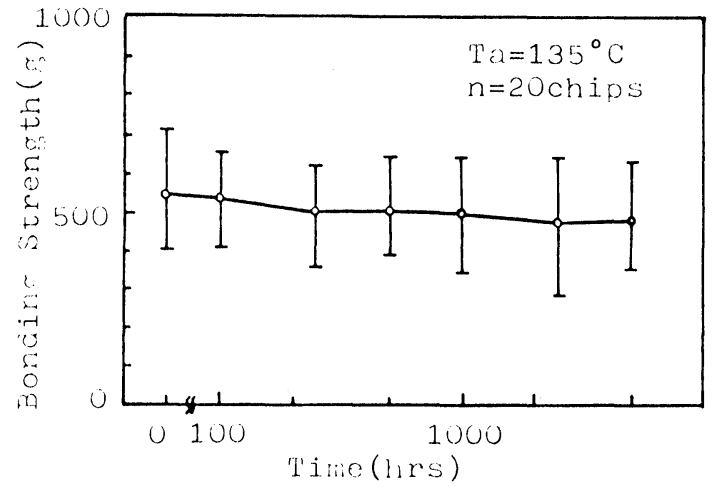

FIGURE 7 Bonding strength after high temperature storage test.

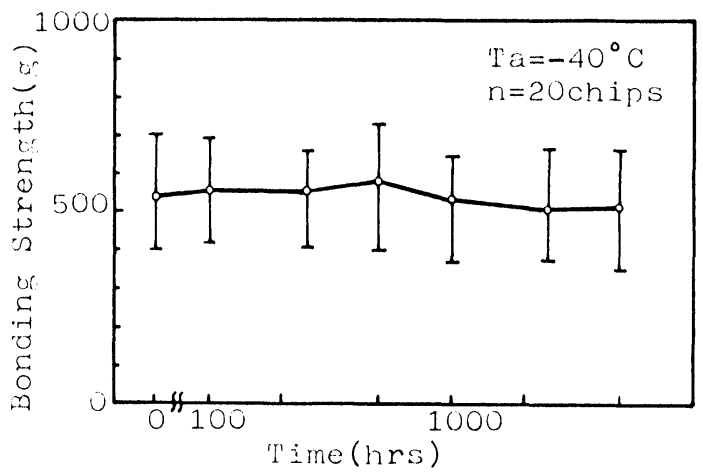

FIGURE 8 Bonding strength after low temperature storage test.

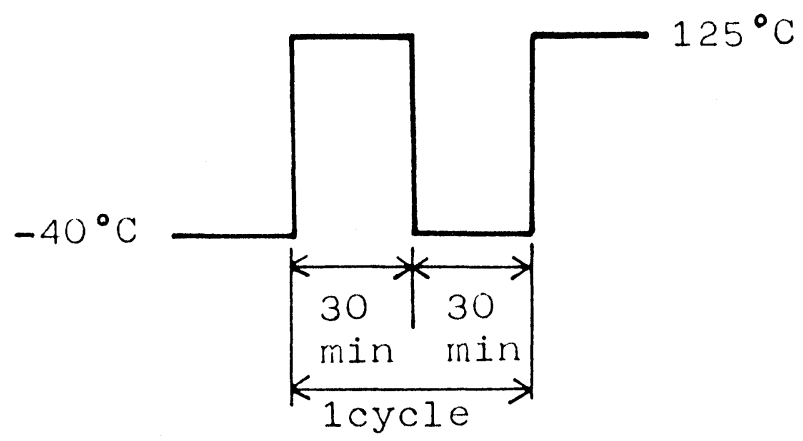

FIGURE 9 Test condition of temperature cycling.
In order to protect chips from mechanical shock in the production process bonded chips are generally coated with rubber which itself causes thermal stress to be applied to the bonding. Given this, the tested samples used for the temperature cycling were originally coated with silicone/rubber for testing. Figure 10 shows the results obtained - bonding strength of the chips remained at the original initial strength.

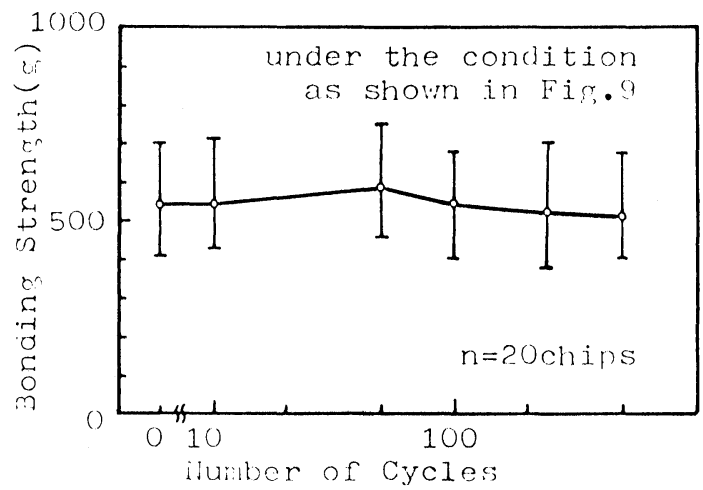

FIGURE 10 Bonding strength after temperature cycling test.

In order to protect integrated circuit chips from the atmosphere the bonded chips are usually housed in hermetic sealed packages or plastic encapsulation. Hermetically sealed chips are easily protected from humidity but in the case of plastic encapsulation it is necessary for the chips to have a low susceptibility to any humidity conditions. For this reason humidity tests were made with uncoated chips at $60^{\circ} \mathrm{C}$ and $95 \%$ humidity and this condition is the same as that recommended by JASO or SAE. ${ }^{3}$ Figure 11 shows the results of such a test.

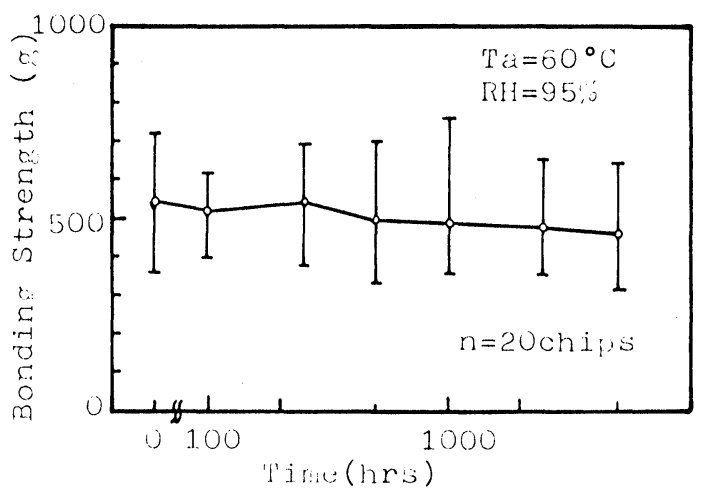

FIGURE 11 Bonding strength after humidity test. 


\section{ELECTRICAL RELIABILITY}

The design of automotive electronics must fully consider the electrical environmental met in use, such as battery voltage changes and various kinds of surge voltages. In order to guarantee reliability under such conditions, electrical endurance tests must be applied to flip chip hybrid circuits used for voltage regulators. In this section the results of such reliability tests will be reported.

The surge voltages experienced can be due to a variety of causes such as the thermal change in circuit loads, use of the ignition system and finally the switching off of inductive loads. The ignition surge voltage is the worst condition experienced and voltages obtained from such a cause can reach values up to 300 volts. With these considerations and given an equivalent circuit of the flip chip hybrid circuit used for an automotive voltage regulator as shown in Figure $12 \mathrm{~b}$, a surge current wave form as shown in Figure 12a was used as a test.

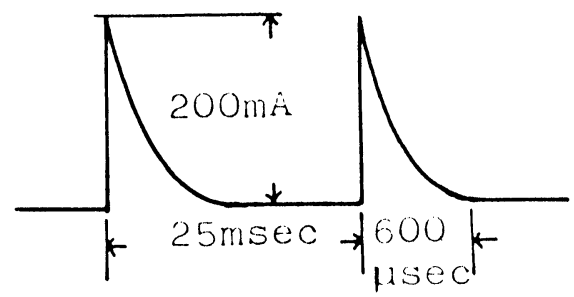

FIGURE 12a Surge current waveform.

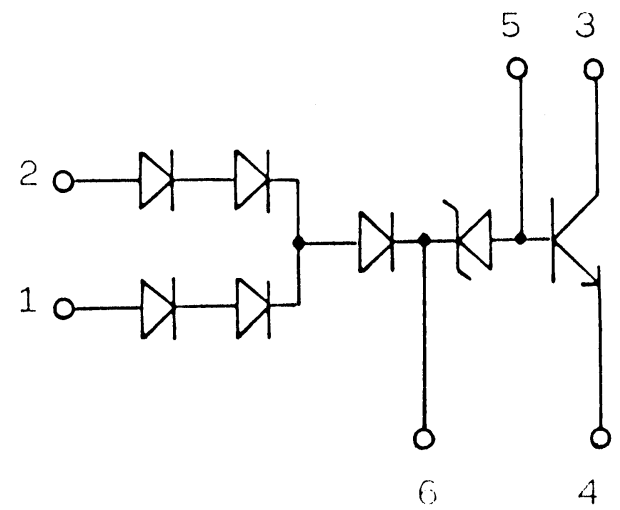

FIGURE 12b Equivalent circuit of flip chip 1C for automotive voltage regulator.
Surge currents were allowed to flow between the first and fourth terminal as in Figure $12 \mathrm{~b}$ at an ambient circuit temperature of $125^{\circ} \mathrm{C}$. The voltage drop between the first and fourth terminal was measured at $1 \mathrm{~mA}$ and $30 \mathrm{~mA}$ as shown in Figure 13. After surge voltages were applied for $2 \times 10^{8}$ cycles, the voltage change observed was less than $\pm 0.1 \%$ from the original value.

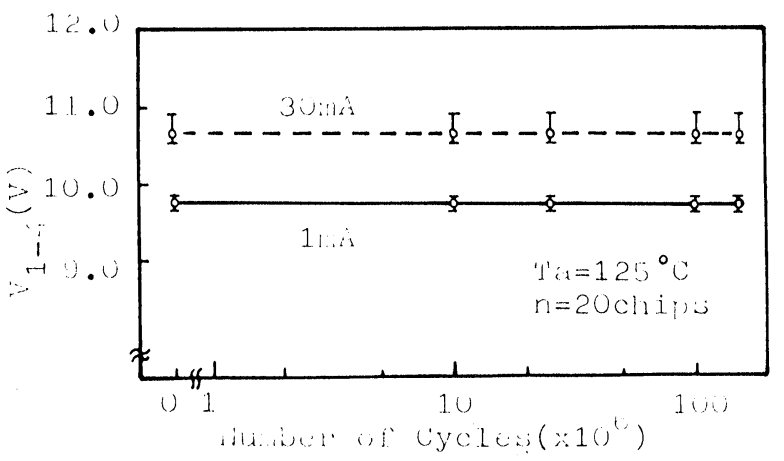

FIGURE 13 Voltage between terminals No. 1 and No. 4 in Figure $12 \mathrm{~b}$ after surge voltage endurance test.

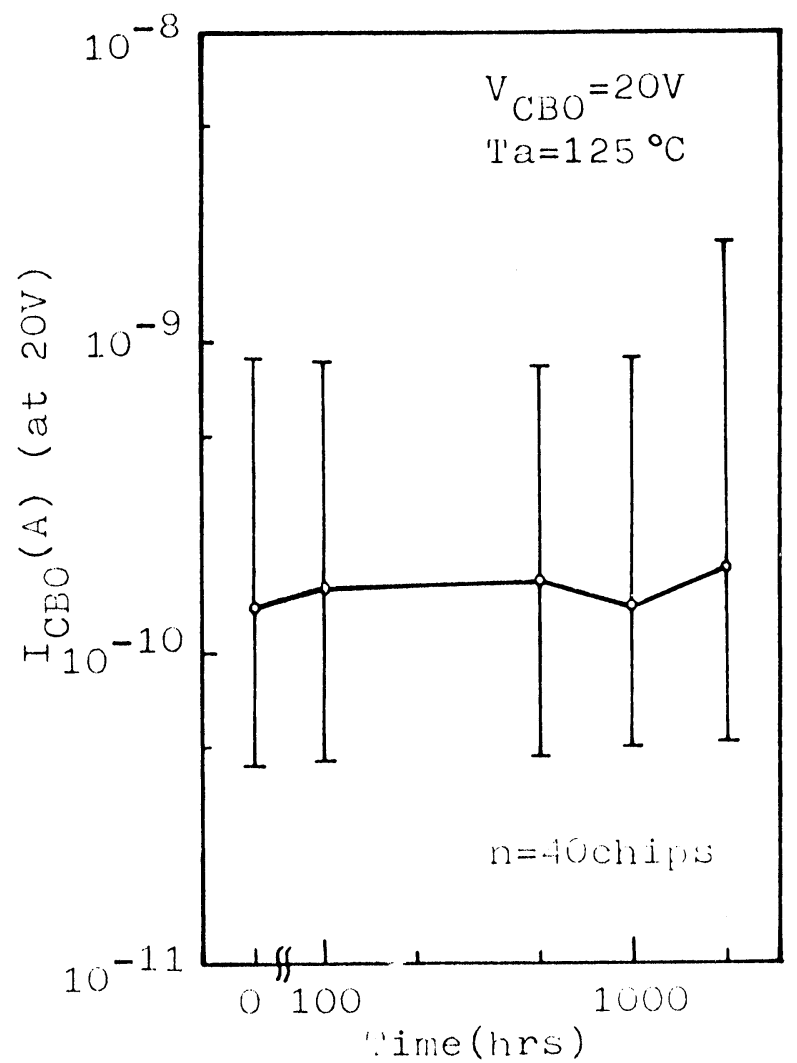

FIGURE 14 Leakage current after bias and temperature test. 
In terms of the electrical reliability of automotive electronics the effect of high temperature operation is considered the most important factor. In order to evaluate this factor even more strictly, the flip chip integrated circuits under test were subject to high temperature tests with a voltage bias applied at the same time. Such a test gave a more accelerated effect than ordinary high temperature testing, particularly with regard to the importance of evaluating the surface passivation technology used. For such a test a maximum applied voltage of about 10 volts is normally used, but we decided to use a bias voltage of 20 volts between the collector and base of our transistors. Results of such tests using an applied temperature, $T_{a}$, of $125^{\circ} \mathrm{C}$, are shown in Figure 14. No change in leakage current was detected after such tests and it can be concluded that the passivation of the devices was satisfactory for automotive electronic applications.

\section{CONCLUSIONS}

It has been shown that flip chip integrated circuits and passive devices attached to thick film circuits can withstand various extreme environmental conditions required for the operation of such circuits in automotive environments. Hybrid circuit voltage regulators constructed using flip chip technology have been tested in the field, and have achieved a failure rate less than $0.001 \%$

It is expected that in the near future more and more automobile electronic circuits will be involved in each automobile and the fact that it has been shown that our flip chip technology together with hybrid circuits can achieve the environmental reliability required indicates that the spread of such applications is likely to be rapid.

\section{REFERENCES}

1. T. Nishi, "Automotive Electronics and Reliability", Electronics parts and materials, 18, No. 5 (1979).

2. A. Ueda, "Integrated Circuit Revolutionizes Automobile Control", Journal of the society of automotive engineers of Japan, 32, No. 2 (1978).

3. F. Minozuma, "Electronics and Motored Vehicles (1) Environmental Conditions and Testing methods", Journal of the society of automotive engineers of Japan, 33, No. 5 (1979). 

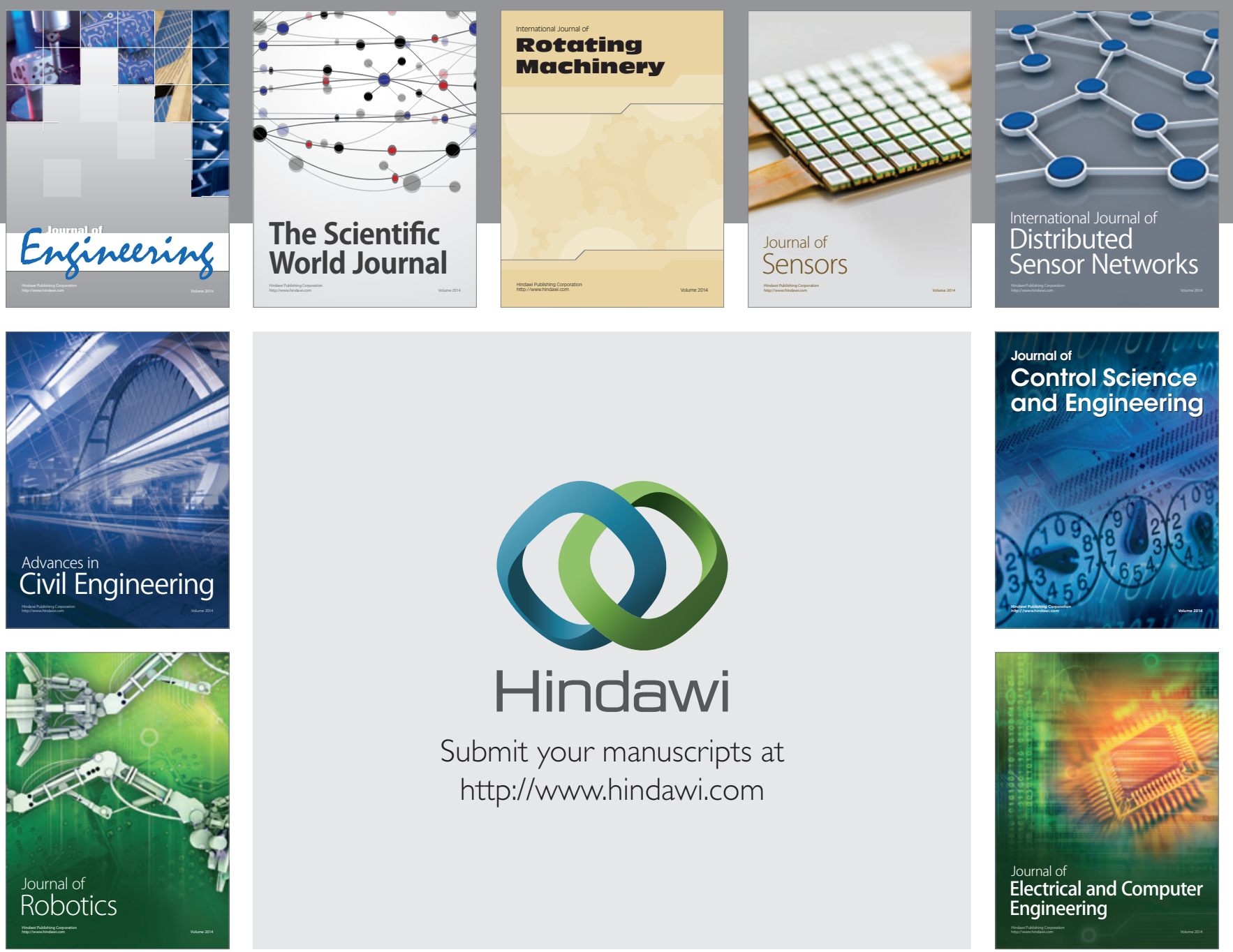

Submit your manuscripts at

http://www.hindawi.com
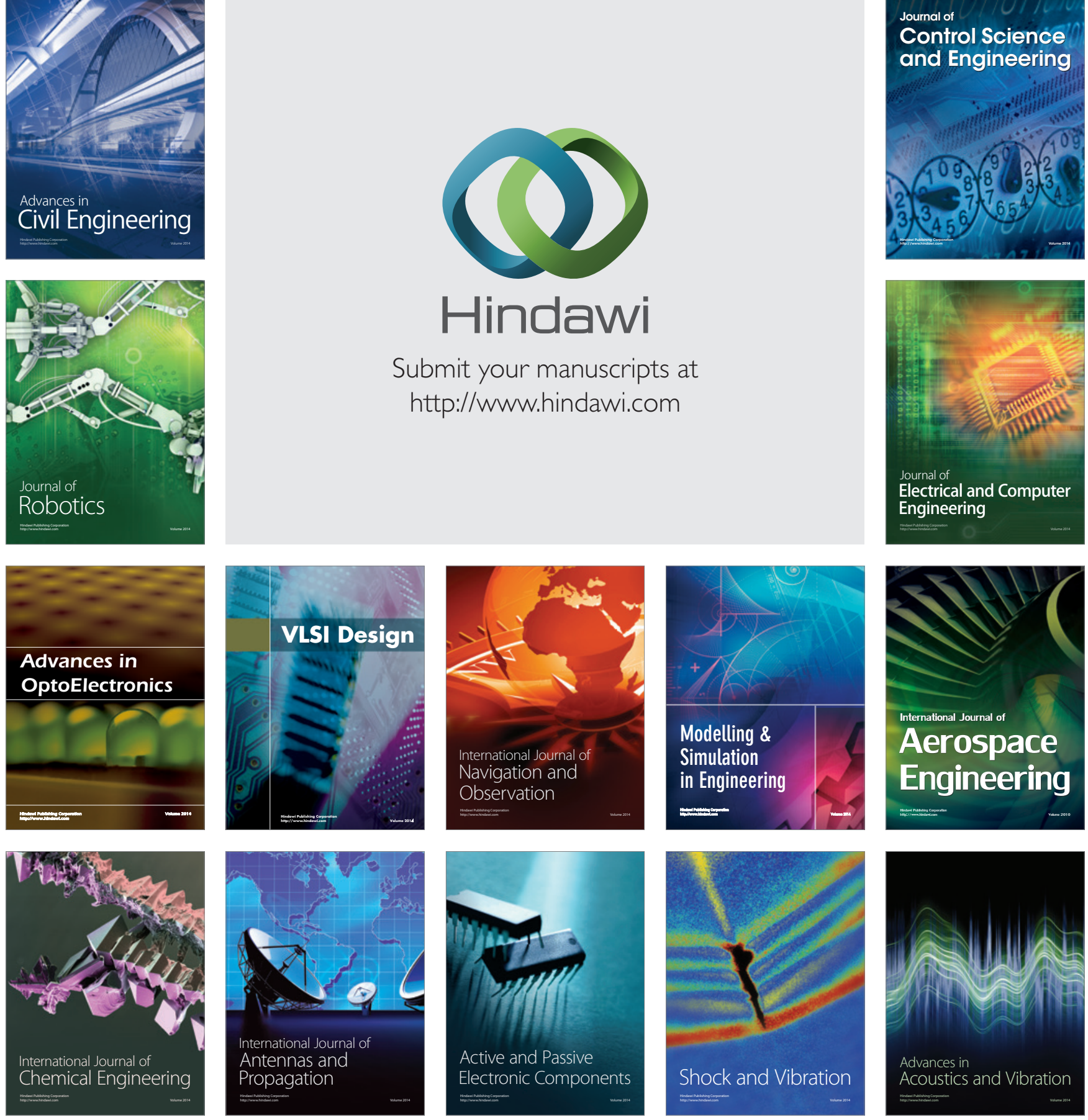